\begin{tabular}{|c|c|c|}
\hline $\begin{array}{l}\text { PKS } \\
\text { PUBLIC } \\
\text { KNOWLEDGE } \\
\text { PROSECT }\end{array}$ & $\begin{array}{c}\text { REVISTA DE GEOGRAFIA } \\
\text { (RECIFE) } \\
\text { http://www.revista.ufpe.br/revistageografia }\end{array}$ & 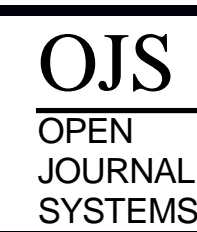 \\
\hline
\end{tabular}

\title{
DETERMINAÇÃO DE REDE DE MONITORAMENTO HIDROSSEDIMENTOLÓGICO NA BACIA DO RIO MACHADINHO-RO
}

\author{
Vinicius Alexandre Sikora de Souza ${ }^{1}$, Claudia Daza Andrade ${ }^{2}$, Otto Correa Rotunno \\ Filho $^{3}$
}

\begin{abstract}
${ }^{1}$ Doutorando em Engenharia Civil pela Universidade Federal do Rio de Janeiro.E-mail: vinicius@coc.ufrj.br ${ }^{2}$ Professora da Universidade Federal Rural do Rio de Janeiro. E-mail: dazaclau@gmail.com

${ }^{3}$ Laboratório de Recursos Hídricos e Meio Ambiente (LABH2O), Programa de Engenharia Civil, Instituto Alberto Luiz Coimbra de Pós-Graduação e Pesquisa de Engenharia - COPPE, Universidade Federal do Rio de Janeiro.E-mail: otto@coc.ufrj.br
\end{abstract}

Artigo recebido em 30/07/2018 e aceito em 02/11/2018

\begin{abstract}
RESUMO
A evolução desordenada de ocupação do solo na bacia do rio Machadinho em Rondônia, na Amazônia ocidental, provoca erosão e degradação hidropedológica dos solos na região, com reflexos de ordem hidrossedimentológica em trechos fluviais que, via de regra, não dispõem de observações coletadas em seções fluviométricas ao longo do rio. Esta pesquisa objetiva formular proposição de concepção e implementação de uma rede de monitoramento. Duas vertentes principais de caracterização de natureza observacional e de procedimento de mensuração balizam o referencial de análise, associando-se notadamente com a avaliação de variáveis dinâmicas, que apresentam padrões de relevante variabilidade, e de variáveis estáticas, que incorporam, por sua vez, aspectos fisiográficos da região de estudo. A aplicação metodológica na bacia, que levou em conta procedimento de ponderação para a alocação do monitoramento, implicou o estabelecimento de uma rede de 10 estações situadas ao longo da bacia, principalmente em zonas de alto fator erosivo, sendo uma delas no seu exutório.
\end{abstract}

Palavras-chave: Rede de monitoramento hidrológico; Hidrometeorologia; Imagens de sensoriamento remoto.

\section{DETERMINATION OF HYDROSEDIMENTOLOGICAL MONITORING NETWORK IN THE MACHADINHO RIVER BASIN-RO}

\begin{abstract}
The disordered evolution of soil occupation in the Machadinho river basin in Rondônia, western Amazonia, causes erosion and hydropedological degradation of the soils in the region with hydrosedimentological impacts in river stretches that usually do not have observations collected in fluviometric sections along the river. In this sense, the commitment of this study is to formulate a proposal of conception and implementation of a monitoring network. Two main aspects with respect to the characterization of observational nature and to the measurement procedure frame the analysis approach, being associated namely with the evaluation of dynamic variables, which present patterns of relevant variability, and of static variables, which incorporate, in turn, physiographic aspects of the region of study. The methodological application in the basin, which took into account the weighting procedure for the allocation of monitoring, implied the establishment of a network of 10 stations located along the basin, especially in zones with high erosive factor, one of them situated in its corresponding outlet.
\end{abstract}

Keywords: Hydrological monitoring network, Hydrometeorology, Remotely sensed images.

Souza, Andrade e Rotunno Filho, 


\section{INTRODUÇÃO}

A bacia hidrográfica do rio Machadinho, localizada no estado de Rondônia, Amazônia Ocidental, sofreu o impacto de diversas transformações que puderam ser acompanhadas ao longo das últimas décadas. A ocupação da bacia ocorreu em processos de colonização, que não respeitaram as diretrizes da legislação ambiental do Brasil (Gomes, 2009).

No contexto proposto, as ações antrópicas resultaram na conversão de extensas áreas de florestas em campos destinados às atividades agropastoris, que, por sua vez, ocasionaram consideráveis impactos nos corpos hídricos. Tais ações desconstruíram áreas de grande importância, como as regiões ripárias, que são consideradas áreas de proteção permanente na legislação ambiental do Brasil. Os principais passivos ambientais são notados com a intensificação dos processos erosivos, o assoreamento de cursos de água e a degradação da qualidade dos solos e das águas.

Identificar áreas de riscos, além de estudar qualitativamente e quantitativamente o problema diagnosticado na região, torna-se um trabalho de difícil realização perante a falta de dados. Adicionalmente, como atestam os estudos de Dias (2014) e de Gontijo Júnior (2007), a região norte do país possui rede fluviométrica esparsa e pouco densa, com limitada eficiência para fins de monitoramento hidráulico-hidrológico.

Diante desse cenário, a determinação de uma rede de monitoramento hidrográfico que leve em consideração as principais características da região, torna-se fator primordial para analisar com maior rigor os riscos hidrossedimentológicos decorrentes de ocupação antrópica não adequadamente planejada.

Em relação às abordagens metodológicas possíveis de serem desenvolvidas e aplicadas, optou-se, neste estudo, pela observância e integração de dois métodos que têm recebido alguma atenção na literatura, como é o caso do procedimento OMM (WMO, 1994) e da diretriz estabelecida por Dias (2014), modificada por Souza (2015). O primeiro indica um número mínimo de estações considerando as condições do relevo da bacia. Já o segundo elabora uma reflexão sobre como melhor configurar uma rede de medições por meio do mapeamento das áreas potenciais para a locação de estações, com a identificação e a seleção de variáveis geoambientais utilizadas nos processos de locação de estações.

Desse modo, emprega-se uma perspectiva integrada dos critérios adotados pela WMO (1994) e por Souza (2015), na medida em que o primeiro indica o número mínimo de estações para compor a rede, enquanto o segundo apropria a localidade que melhor se ajusta à 
instalação. A essa concepção metodológica, aliam-se os trabalhos de Galvão (2004) e Diniz et al. (2008).

A abordagem contribui com um novo olhar para conceber a configuração de uma rede de monitoramento que seja potencialmente adequada para atender e mensurar, com maior rigor, a evolução da paisagem ambiental e do domínio espaço-temporal hidrológico.

\section{MATERIAL E MÉTODOS}

Área de estudo

A bacia hidrográfica do rio Machadinho (Figura 1) situa-se no estado de Rondônia e integra o grupo das principais bacias do estado. A bacia localiza-se na Amazônia Ocidental, na porção centro-leste de Rondônia, abrangendo área com extensão de $5.485,41 \mathrm{~km}^{2}$, com inserção no domínio de quatro municípios, sendo eles Machadinho d'Oeste, Vale do Anari, Ariquemes e Theobroma. A importância da bacia é significativa, pois é responsável pelo abastecimento de água da sede do município de Machadinho D’Oeste (Souza, 2015).

Figura 1 - Mapa de localização da bacia hidrográfica do rio Machadinho-RO.

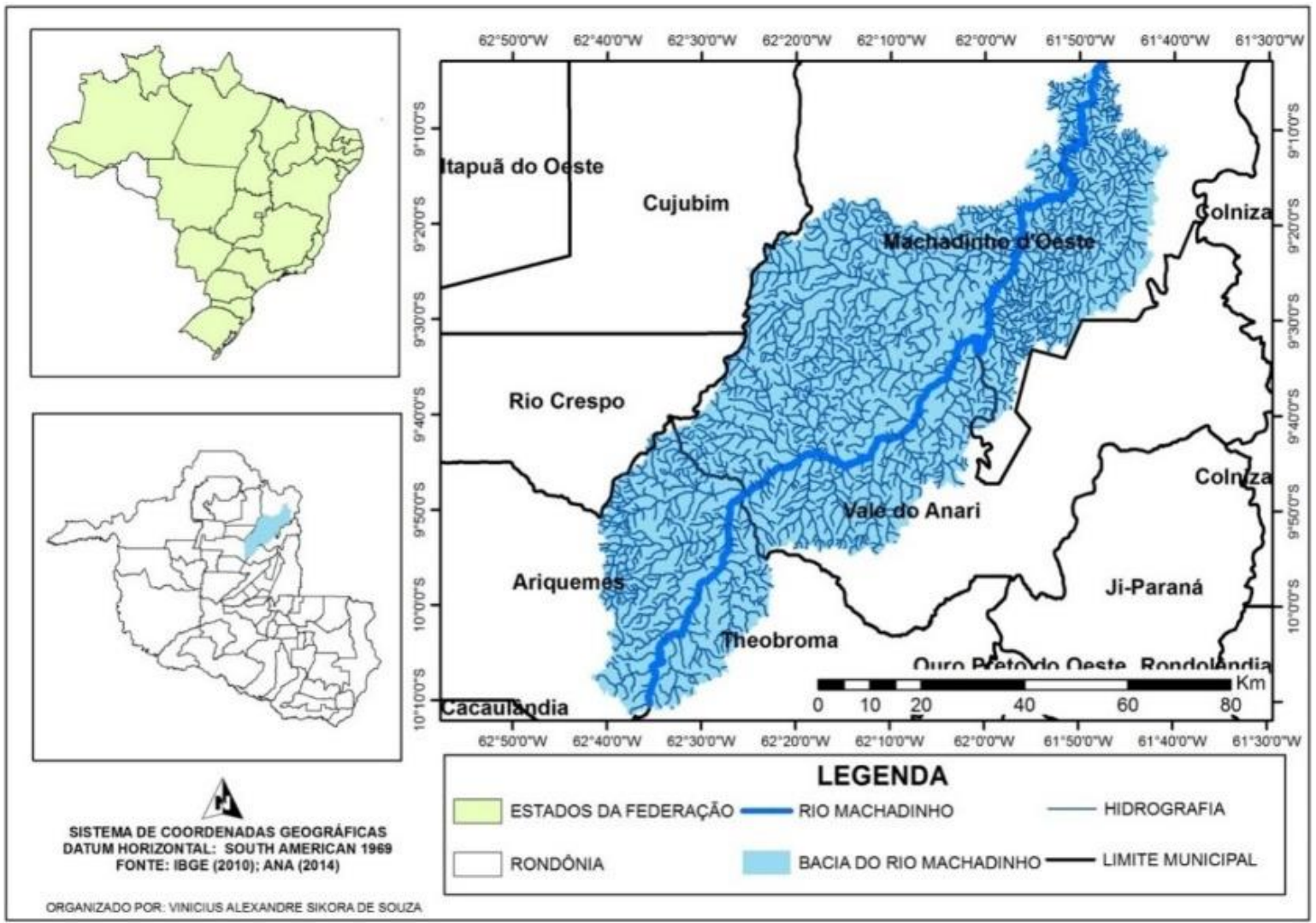


Determinação da rede hidrossedimentológica

O dimensionamento realizado para a rede hidrossedimentológica atendeu os pressupostos do método da OMM. Por outro lado, o posicionamento das estações seguiu o método de álgebra de mapas para atender determinados critérios pré-estabelecidos na metodologia adotada.

No posicionamento da rede, objetivou-se identificar áreas potencialmente mais propensasao monitoramento, dada a sobreposição de camadas operadas no nível de resolução do píxel da ordem de $30 \mathrm{~m}$, com variáveis de interesse e seus respectivos pesos (Tabela 1). Tais camadas foram escolhidas considerando características que influem no ciclo hidrológico, na produção e na distribuição dos sedimentos na área de estudo, podendo, no futuro, caso instalada a rede, gerar dados para monitorar fenômenos hidrossedimentológicos na região.

Além disso, na análise, empregaram-se variáveis dinâmicas e estáticas, com base nos pressupostos apresentados em Souza (2015). Nas variáveis dinâmicas, levou-se em consideração o desvio padrão de uma série histórica, onde o de menor magnitude indicaria uma certa estabilidade e maior confiabilidade, sendo atribuída maior pontuação.

Na Tabela 1, são apresentadas as variáveis que influenciam a hidrossedimentologia, com as suas respectivas classes e pesos (Tabela 1). Em particular, para essa ponderação, optou-se pelos pesos empregados por Galvão (2014) em estudo realizado na região da Amazônia e no rio São Francisco. Os pesos obtidos foram atribuídos em função da influência do evento hidrossedimentológico e da logística de alocação. 
Tabela 1 - Variáveis e pesos empregados.

\begin{tabular}{|c|c|c|c|}
\hline Classes & Atributos & Influência & Pesos \\
\hline \multirow[t]{5}{*}{ Uso e ocupação da superfície } & Área urbana & \multirow[t]{5}{*}{$20 \%$} & 1 \\
\hline & Pastagem & & 0,8 \\
\hline & Água & & 0 \\
\hline & Floresta de terra firme & & 0,2 \\
\hline & Floresta propensa a inundação & & 0,2 \\
\hline \multirow[t]{6}{*}{ Declividade } & Relevo plano & \multirow[t]{6}{*}{$10 \%$} & 1 \\
\hline & Relevo suavemente ondulado & & 0,8 \\
\hline & Relevo ondulado & & 0,6 \\
\hline & Relevo fortemente ondulado & & 0,4 \\
\hline & Relevo montanhoso & & 0,2 \\
\hline & Relevo fortemente montanhoso & & 0,1 \\
\hline Susceptibilidade erosiva & - & $40 \%$ & $0-1$ \\
\hline $\begin{array}{l}\text { Variação } \\
\text { evapotranspiração }\end{array}$ & - & $15 \%$ & $0-1$ \\
\hline $\begin{array}{l}\text { Variação da temperatura de } \\
\text { superfície }\end{array}$ & - & $15 \%$ & 0 \\
\hline
\end{tabular}

- Declividade

A declividade da bacia foi determinada usando imagens do satélite Aster, tratadas com o filtro "FILL" para eliminação de depressões espúrias. Os terrenos de menor declividade, considerados como os mais planos, obtiveram maiores pesos em função do melhor acesso para a instalação da estação.

- Uso e Ocupação da Superfície do Solo

Para o mapa de uso e ocupação do solo da bacia do rio Machadinho, utilizaram-se imagens do sensor TM (Thematic Mapper) do satélite LANDSAT 5 para o ano de 2011, fornecidas pela U.S. Geological Survey Global Visualization Viewer (USGS Glovis). 
- Temperatura

As informações referentes à temperatura de superfície da bacia do rio Machadinho foram obtidas por meio do sensor Moderate Resolution Imaging Spectroradiometer (Modis), mediante seu produto MOD11A2 (Land Surface Temperature- LST), coleção 5, com resolução espacial de $1 \mathrm{~km}$. Foram obtidas juntamente a NASA e especializadas no quadrante v 11 e h 9.

- Evapotranspiração

A estimativa da evapotranspiração foi realizada a partir de dados de sensoriamento remoto por satélite. As imagens empregadas nesse processo foram as do satélite MODIS, produto MOD16, com resolução de píxel de $1 \mathrm{~km}$ em seu nível A2, consistidas pela National Aeronautics and Space Administration (NASA) para a remoção de contaminação de nuvens e interpoladas em resolução temporal de 8 dias. Essas informações foram obtidas junto a própria NASA, sendo o período de análise compreendido entre 2000 a 2008, notando-se que a correspondente espacialização foi a mesma das imagens utilizadas para a temperatura de superfície v 11 e h 9.

- Susceptibilidade Erosiva

A susceptibilidade erosiva foi determinada por meio da interposição de pesos em camadas (Tabela 2). Seguiu-se a metodologia usada por Diniz et al. (2008), entretanto alguns pesos foram obtidos por meio do estudo de CPRM (2007). Posteriormente, houve a normalização para a região a fim de estabelecer um grau variando de 0 a 1 .

Tabela 2 - Variáveis utilizadas na determinação da susceptibilidade erosiva.

\begin{tabular}{|c|c|c|c|}
\hline Classes & Atributos & Influência & Pesos \\
\hline \multirow{5}{*}{$\begin{array}{l}\text { Uso } \\
\text { ocupação da } \\
\text { superfície solo }\end{array}$} & Área urbana & \multirow[t]{5}{*}{$20 \%$} & 4 \\
\hline & Pastagem & & 8 \\
\hline & Água & & 0 \\
\hline & Floresta de terra firme & & 2 \\
\hline & Floresta propensa a inundação & & 2 \\
\hline \multirow[t]{2}{*}{ Declividade } & Relevo plano & \multirow[t]{2}{*}{$30 \%$} & 1 \\
\hline & Relevo suavemente ondulado & & 2 \\
\hline
\end{tabular}

Souza, Andrade e Rotunno Filho, 2018 


\begin{tabular}{|c|c|c|c|}
\hline & Relevo ondulado & & 4 \\
\hline & Relevo fortemente ondulado & & 6 \\
\hline & Relevo montanhoso & & 8 \\
\hline & Relevo fortemente montanhoso & & 10 \\
\hline \multirow[t]{10}{*}{ Elevação } & Nível 1 & \multirow[t]{10}{*}{$5 \%$} & 1 \\
\hline & Nível 2 & & 2 \\
\hline & Nível 3 & & 3 \\
\hline & Nível 4 & & 4 \\
\hline & Nível 5 & & 5 \\
\hline & Nível 6 & & 6 \\
\hline & Nível 7 & & 7 \\
\hline & Nível 8 & & 8 \\
\hline & Nível 9 & & 9 \\
\hline & Nível 10 & & 10 \\
\hline \multirow[t]{7}{*}{ Solo } & Regossolo Eutrófico & \multirow[t]{7}{*}{$20 \%$} & 9 \\
\hline & Gleissolo Distrófico & & 3 \\
\hline & Latossolo Amarelo Distrófico & & 5 \\
\hline & Latossolo Vermelho-Amarelo Distrófico & & 5 \\
\hline & Latossolo Vermelho-Escuro Distrófico & & 5 \\
\hline & Latossolos Vermelho-Escuro Eutrófico & & 7 \\
\hline & Latossolo Vermelho-Amarelo Eutrófico & & 7 \\
\hline \multirow[t]{9}{*}{ Geologia } & Coberturas detrito-lateríticas & \multirow[t]{9}{*}{$10 \%$} & 5 \\
\hline & Coberturas sedimentares indiferenciadas & & 5 \\
\hline & Depósitos Aluvionares & & 5 \\
\hline & Jamari & & 4 \\
\hline & Palmeiral & & 5 \\
\hline & Quatro Cachoeiras & & 4 \\
\hline & Rondônia (Younger Granites) & & 3 \\
\hline & Santa Clara & & 3 \\
\hline & Serra da Providência & & 3 \\
\hline Geomorfologia & Planícies fluviais & $15 \%$ & 3 \\
\hline
\end{tabular}




\begin{tabular}{|l|l|l|l|}
\hline & $\begin{array}{l}\text { Níveis de Superfície de Aplanamento com cotas } \\
\text { inferiores a 200m }\end{array}$ & 4 \\
\cline { 1 - 1 } & $\begin{array}{l}\text { Níveis de Superfície de Aplanamento com cotas } \\
\text { de } 200-300 m\end{array}$ & 5 \\
\cline { 2 - 3 } & Agrupamentos de morros e colinas & 6 \\
\cline { 2 - 3 }
\end{tabular}

- Número e Localização das Estações na Rede Hidrossedimentológica

O número de estações obedeceu aos pressupostos destacados pela Organização Meteorológica Mundial - WMO (1984) (Tabela 3).

Tabela 3 - Densidade mínima de monitoramento fluviométrico segundo WMO (1984).

\begin{tabular}{|l|l|}
\hline Relevo & Densidade Mínima $\left(\mathbf{K m}^{2} /\right.$ Estação) \\
\hline Costeiro & 900 \\
\hline Montanhoso & 250 \\
\hline Planícies Interiores & 575 \\
\hline Levemente Ondulado & 575 \\
\hline Pequenas Ilhas & 25 \\
\hline Regiões Polares/Áridas & 10.000 \\
\hline
\end{tabular}

A disposição das estações na bacia hidrográfica do Machadinho seguiu o critério de área com maior média ponderada de potencial à locação de estações, com exceção do exutório da bacia, onde se determinou localizar uma estação como obrigatória.

Para definir as possíveis localidades de distribuição, criaram-se, primeiramente, pontos na intersecção dos trechos dos corpos hídricos que possuíam regime permanente, utilizandose, assim, a conformação (shape) da hidrografia em detalhamento de 1:100.000.

Após esse procedimento, gerou-se a área de influência de cada ponto por meio dos diagramas de Voronoi (Figura 3), os quais formam polígonos por meio de mediatrizes das linhas que ligam dois postos adjacentes (Pruski et al., 2004). 
Figura 3 - Possíveis localizações das estações hidrossedimentológicas e suas áreas de influência.

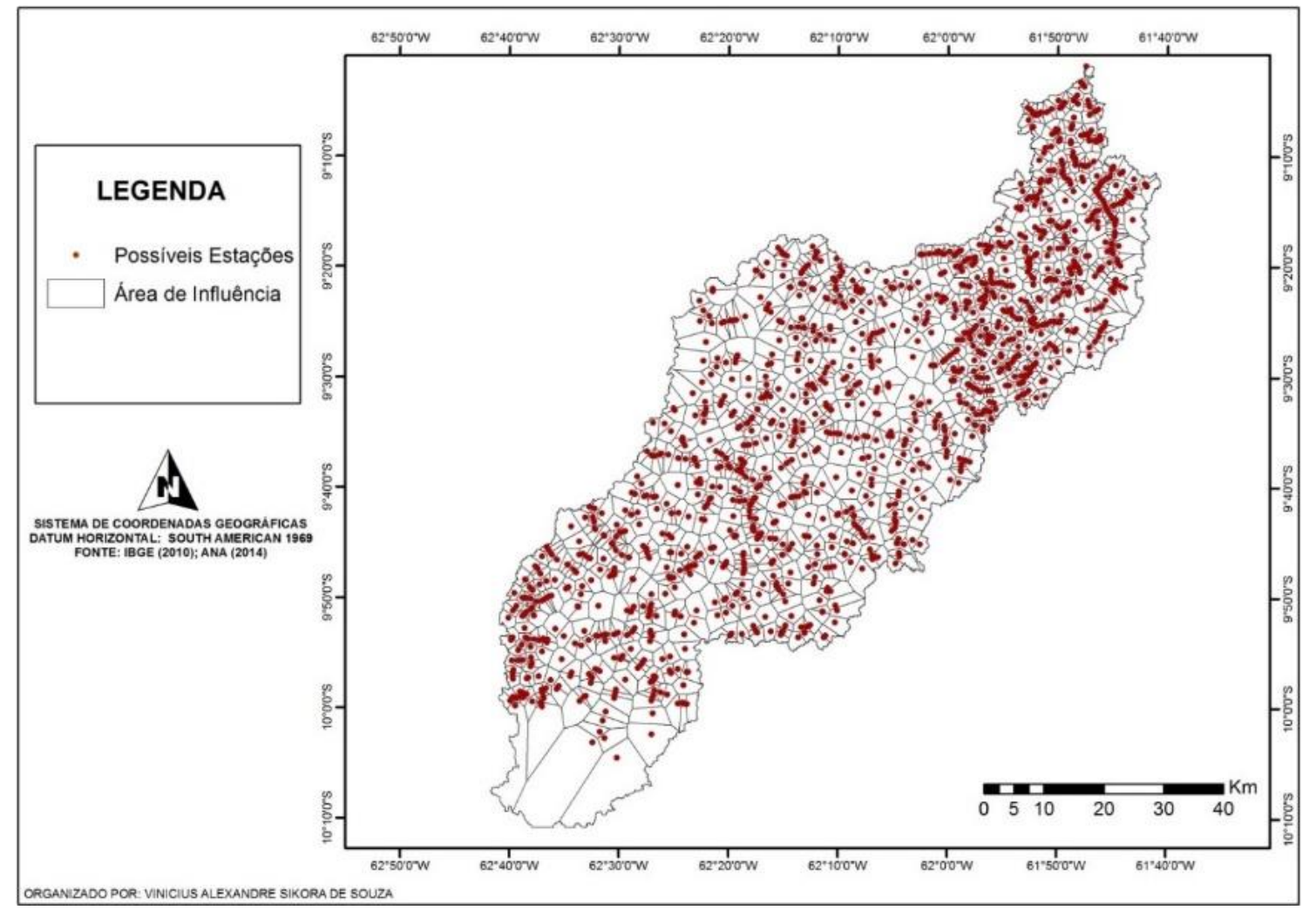

Uma vez determinadas as áreas de influência, seccionou-se a matriz (raster) de indicação do potencial à locação de estações hidrossedimentológicas para cada área; extraiuse, posteriormente, a média em cada área, sendo essas organizadas conforme o seu valor, para que, assim, fossem escolhidas as estações nas primeiras posições em número suficiente para atender a Organização Meteorológica Mundial.

Cabe ainda ressaltar que, para estabelecer uma melhor distribuição espacial da rede, as estações com as maiores aptidões de instalação, mas que continham suas áreas de influência contíguas, foram retiradas. Em seguida, selecionou-se, dentre essas estações, apenas uma que estivesse em um corpo hídrico de maior classe, eliminando, assim, a concentração de grande número de estações em pequena área. Dessa maneira, a estação que possuía uma ordem de aptidão um pouco inferior passou a assumir a posição da estação excluída. 


\section{RESULTADOS E DISCUSSÃO}

\section{Elevação e declividade}

Os mapas altimétrico e clinográfico da bacia do rio Machadinho estão exibidos na Figura 4.

Figura 4 - a) Mapa altimétrico da bacia do rio Machadinho; b) Mapa clinográfico da bacia do rio Machadinho.

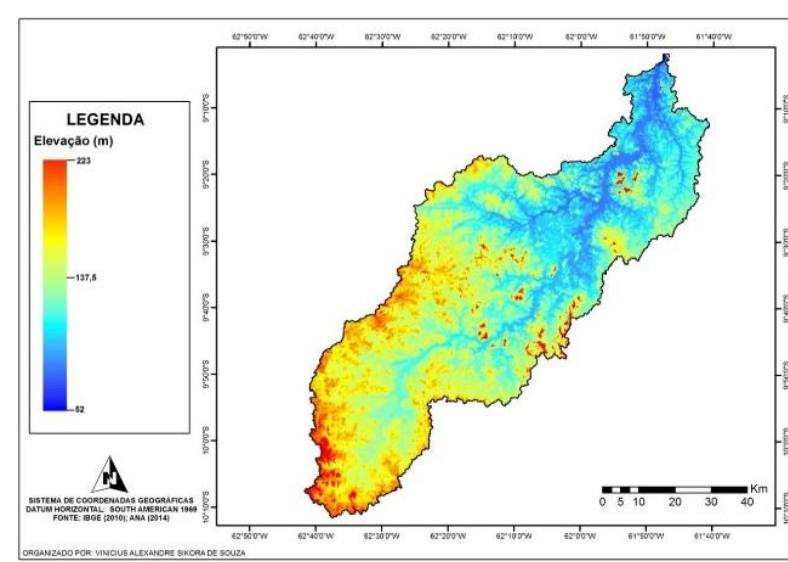

a)

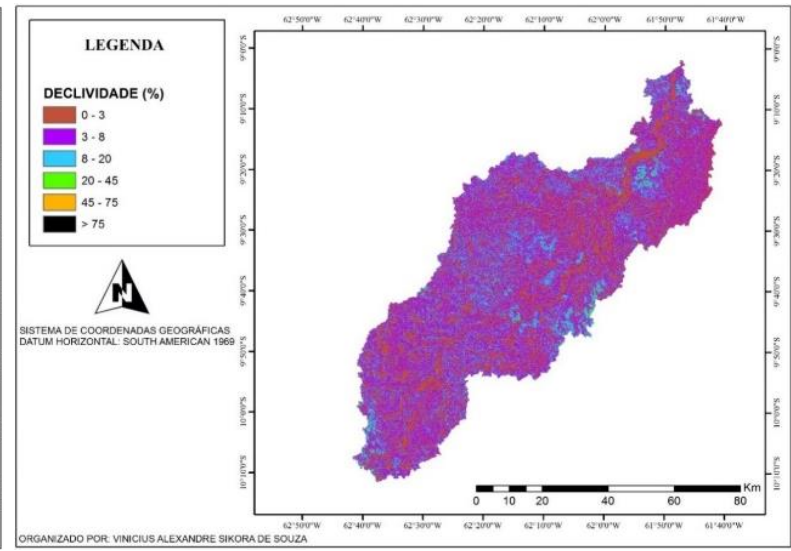

b)

A altitude na bacia varia de $223 \mathrm{~m}$ a $52 \mathrm{~m}$, com média de $92,11 \mathrm{~m}$. As maiores altitudes ocorrem nas proximidades das nascentes dos principais rios, ao sul da bacia, em uma região de agrupamentos de morros e colinas. Já o ponto mais baixo localiza-se no exutório da bacia.

Verifica-se que grande parte da bacia apresenta valores de declividade inferiores a $8 \%$, constando, assim, que o relevo da região varia de plano a suavemente ondulado em cerca de $89,3 \%$ da área da bacia.

Os valores mais baixos encontram-se nas vertentes próximas aos cursos de água. Verificou-se que o valor máximo de declividade observado na bacia foi de $94,24 \%$, enquanto o valor médio foi de 4,62\%. Portanto, observa-se que, na área de estudo, há o predomínio de declividades baixas típicas de planícies.

\section{Geologia e geomorfologia}

Na Figura 5, estão os mapas de geologia e geomorfologia da região de estudo. 
Figura 5 - a) Mapa geológico; b) Mapa geomorfológico da bacia do rio Machadinho.

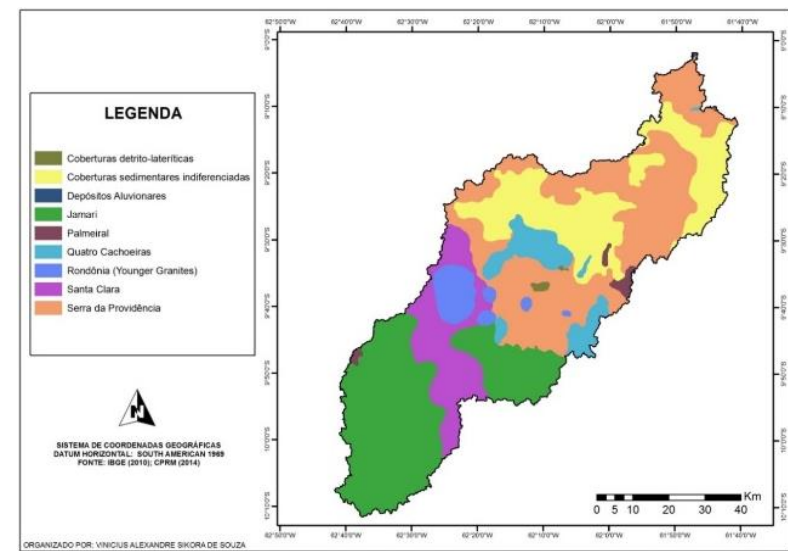

a)

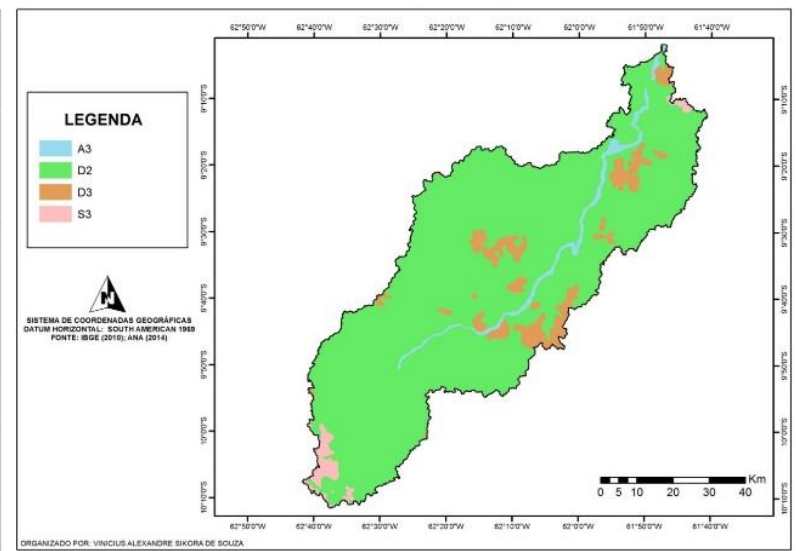

b)

Os principais afloramentos de rochas na bacia do rio Machadinho são pertencentes ao complexo Jamari, à suíte metamórfica Quatro Cachoeiras, à suíte intrusiva Serra da Providência, à suíte intrusiva Santa Clara e à suíte intrusiva Rondônia.

O complexo Jamari encontra-se representado estratigraficamente pelo embasamento cristalino pré-cambriano; compreende unidades litoestratigráficas e sistemas estruturais envolvidos em longa geodinâmica, com registros nos primórdios do paleoproterozóico (1,8 a 1,6 bilhões de anos), culminando, segundo BACCI (2005), com a deposição das chamadas coberturas cenozóicas num período mais recente (2 milhões de anos até o presente).

No que tange à suíte metamórfica Quatro Cachoeiras, pode-se dizer que é composta de migmatitos pelíticos, xistos, calciossilicáticas, kinzigitos e hematita quartzitos.

Já a suíte intrusiva Serra da Providência é composta por granitos com textura rapakivi, charnockitos, mangerito e gabros, ocorrendo como stocks isotrópicos a deformados, intrusivos no complexo Jamari (Quadros e Rizotto, 2007).

A geomorfologia da bacia do rio Machadinho aponta particularidades morfológicas associadas às categorias de agradação (unidades deposicionais ou agradacionais) e degradação (unidades denudacionais).

As unidades agradacionais sofreram fenômenos de acúmulo de sedimentos provenientes dos desgastes induzidos pela a ação de agentes exodinâmicos (RONDÔNIA, 2002). São constituídas de zonas de depressão relativas; para a bacia do rio Machadinho, ocorrem planícies fluviais. 
Planícies fluviais (A3) são unidades de deposição de material particulado e localizamse nas adjacências dos cursos de água, estando associadas às planícies fluviais de drenagens.

No que concerne às unidades denudacionais, essas são formas de relevo que passaram por processo de denudação, responsáveis pelo progressivo rebaixamento do terreno. As seguintes unidades denudacionais são observadas na bacia estudada:

- níveis de superfície de aplanamento - são arrasamentos generalizados remanescentes do relevo, gerados por processos erosivos; trata-se de superfícies arrasadas progressivamente por meio de lenta denudação através de um processo de rebaixamento do nível de base (RONDÔNIA, 2002); D3- as cotas atingidas por essa superfície distribuem-se no intervalo de $200 \mathrm{~m}$ - $300 \mathrm{~m}$; D2- as cotas atingidas por essa superfície são inferiores a $200 \mathrm{~m}$;

- agrupamentos de morros e colinas (S3) - são feições geomorfológicas associadas a morros e colinas dispersas regionalmente; são relevos residuais, associados a diferentes rochas do embasamento cristalino, não possuindo controle estrutural nítido.

\section{Solos}

A Tabela 3 e o mapa de solos na Figura 6 mostram que os solos do tipo argissolo vermelho-amarelo distrófico ocupam mais da metade de toda área da bacia do Machadinho, perfazendo um total de aproximadamente $56 \%$. Cabe frisar que uma elevada parte da bacia possui solos eutróficos, predominantemente latossolos, com potencial agrícola, ao contrário do que ocorre na maior parte do estado, em que há predominância de solos antigos, extremamente intemperizados, com baixos níveis de nutrientes, elevada acidez, baixa capacidade de troca catiônica e condições de drenagem pobre (Krusche et al., 2005).

Tabela 3 - Distribuição dos solos na bacia do rio Machadinho

\begin{tabular}{|l|l|l|}
\hline Sigla & Tipo de solo & Área relativa (\%) \\
\hline EE & Regossolo Eutrófico & 0,32 \\
\hline GD & Gleissolo Distrófico & 1,97 \\
\hline LAD & Latossolo Amarelo Distrófico & 9,03 \\
\hline LLD & Latossolo Vermelho-Amarelo Distrófico & 56,31 \\
\hline LVD & Latossolo Vermelho-Escuro Distrófico & 7,23 \\
\hline
\end{tabular}




\begin{tabular}{|l|l|l|}
\hline LVE & Latossolos Vermelho-Escuro Eutrófico & 21,41 \\
\hline LLE & Latossolo Vermelho-Amarelo Eutrófico & 3,73 \\
\hline
\end{tabular}

Figura 6 - Mapa de solos da bacia do rio Machadinho.

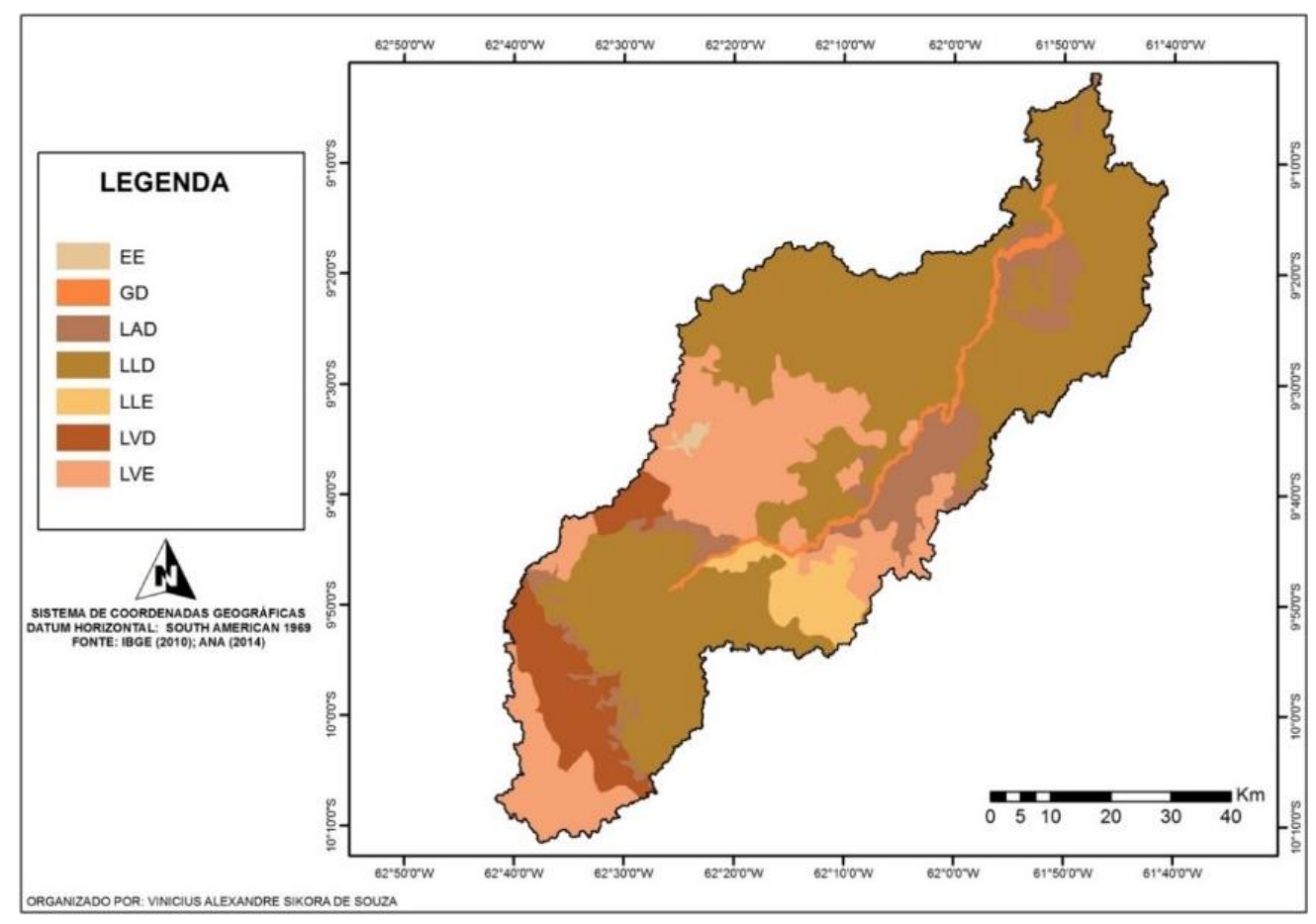

Temperatura e evapotranspiração

As variações de temperatura de superfície e evapotranspiração estão na Figura 7.

Figura 7 - a) Desvio padrão da temperatura de superfície da bacia do rio Machadinho de 2003 a 2013 (superior); b) Desvio padrão da evapotranspiração em período de 8 dias da bacia do rio Machadinho de 2000 a 2013 (inferior). 


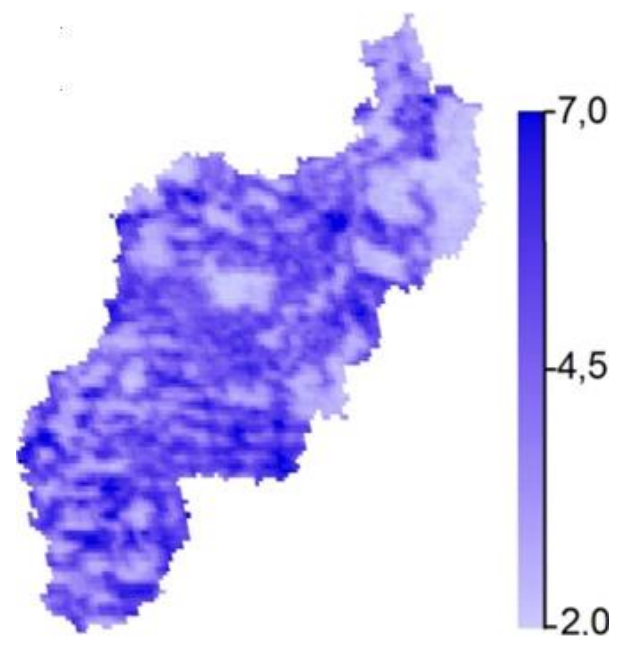

a)

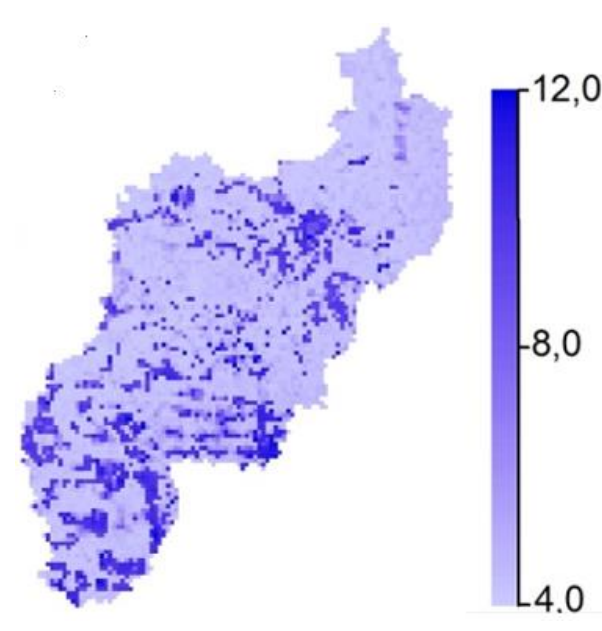

b)

A distribuição da temperatura mostra certa homogeneidade, sendo as variações em áreas com mata nativa bem inferiores àquelas que ocorrem em outros espaços de uso e ocupação, dado que os desvios padrões tendem a ficarem mais próximos de $0^{\circ} \mathrm{C}$.

Os desvios padrões da evapotranspiração pouco acentuados revelam que, nesse período de 14 anos, não se verificaram grandes anomalias climáticas que pudessem influir em grandes mudanças desse fenômeno na bacia.

\section{Uso e ocupação da bacia e susceptibilidade erosiva}

Na Figura 8, é apresentada o mapeamento do uso e ocupação do solo da bacia do rio Machadinho gerado a partir da classificação supervisionada de imagens Landsat5, onde foram estabelecidas as seguintes classes: (1) área urbana; (2) água; (3) pastagem; (4) floresta de terra firme; e (5) floresta propensa a inundação. 
Figura 8 - Uso e ocupação da superfície do solo na bacia do rio Machadinho.

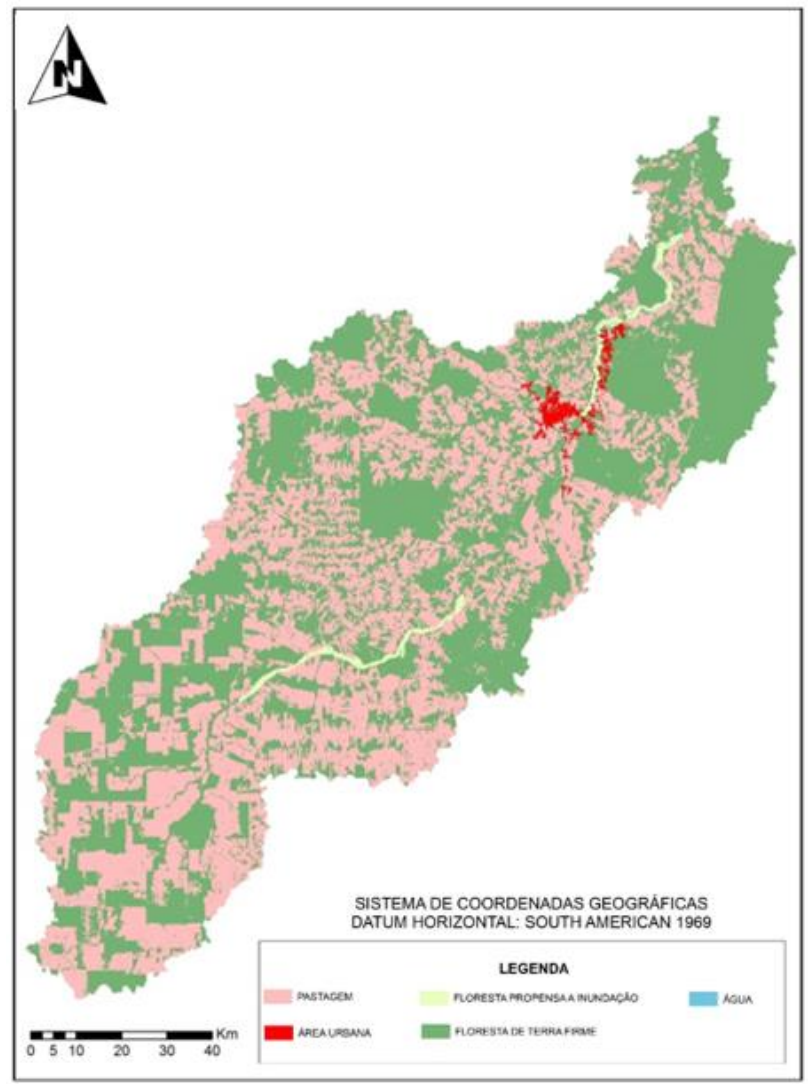

As porções de pastagem e de área urbana constituíram, respectivamente, quantitativos próximos de $46 \%$ e de $0,7 \%$ da área da localidade. A vegetação está presente em pouco mais de $50 \%$ da área total da bacia.

A classe área urbanizada ocorre em uma pequena parte da bacia, correspondendo ao perímetro urbano do município de Machadinho d'Oeste. Essa classe é pouco representativa, contudo Souza (2015) destaca que a mesma vem apresentando um crescimento acentuado com o passar dos anos.

É nítida a ocupação de grande escala, o que pode propiciar inúmeros malefícios para esse corpo hídrico, tal como uma maior tendência do solo erodir, fato que pode ser contrastado com a susceptibilidade à erosão no terreno da bacia, que se encontra exibido na Figura 9. 
Figura 9 - Susceptibilidade erosiva da bacia do rio Machadinho

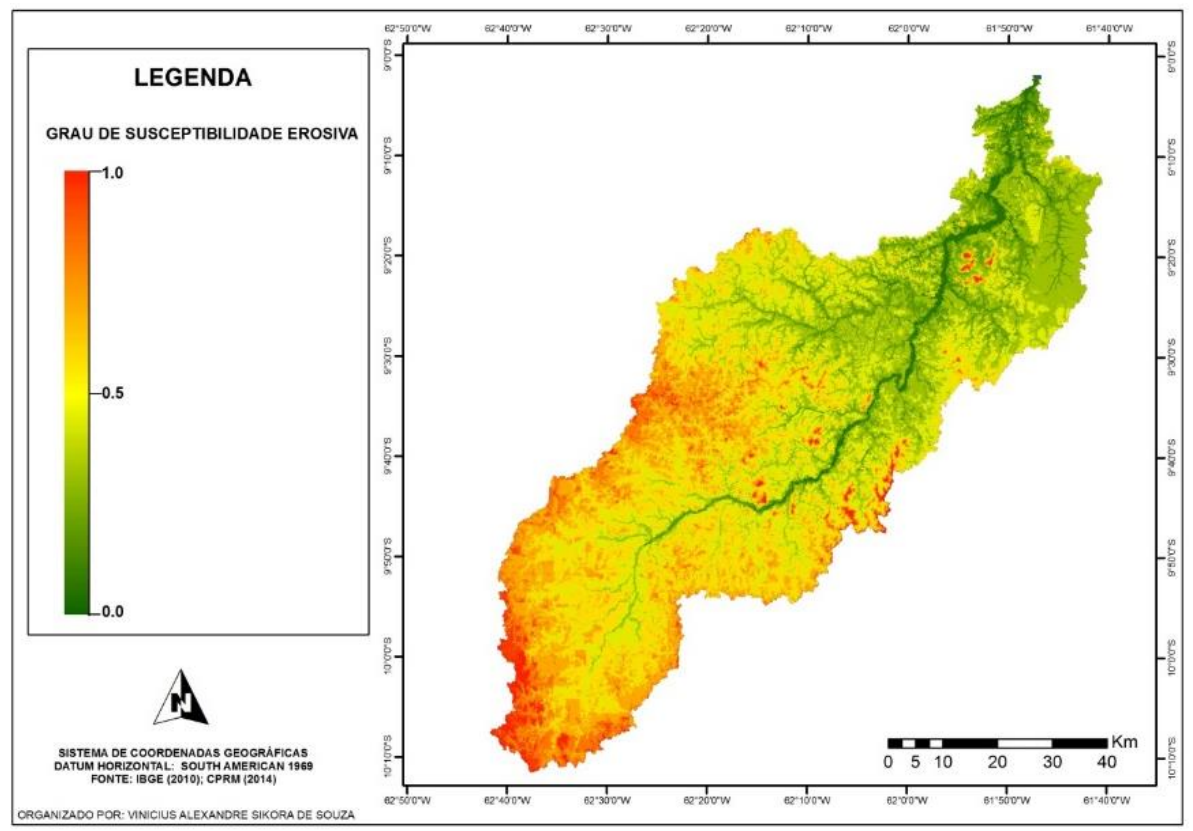

O fator de conversão de floresta em pastagem é o maior responsável pelas zonas de grande susceptibilidade erosiva, visto que a declividade, que consiste no fator de maior ponderação na metodologia empregada, não é acentuada na área, sendo grande parte do relevo da região plano a suavemente ondulado.

Adicionalmente, os solos, que, juntamente com o fator de uso e ocupação, possuem os segundos maiores níveis de influência na susceptibilidade erosiva, denotam, na maior parte da bacia, características distróficas, tendendo, assim, a serem menos propensos a processos erosivos.

Por fim, verifica-se, ainda, que, na presença de pastagem, principalmente na nascente do rio, a bacia apresenta grau mais elevado (próximo de 1), enquanto, em zonas de floresta, esse grau reduz-se. Portanto, as nascentes têm o agente formador de paisagem em desequilíbrio devido à dinâmica de transformação antropogênica, provocando, assim, um processo de retroalimentação erosivo descompensado. 
Proposta de rede hidrossedimentológica

Segundo a WMO (1984), o quantitativo mínimo recomendado de estações que deve compor essa rede é de 10 unidades, pois o relevo da região é basicamente formado de planícies interiores e por aspectos levemente ondulados.

No que tange à distribuição dessas estações (Figura 10), seguindo o mapa de aptidão de alocação de estações, observa-se certa predominância na região das nascentes. Tal tendência é explicada pela alta conversão de floresta em pastagem, que é expressivamente intensa nessa localidade em relação ao restante da bacia, provocando, assim, maior susceptibilidade erosiva (Souza, 2012).

Figura 10 - Localização da rede hidrossedimentológica para a bacia do rio Machadinho-RO

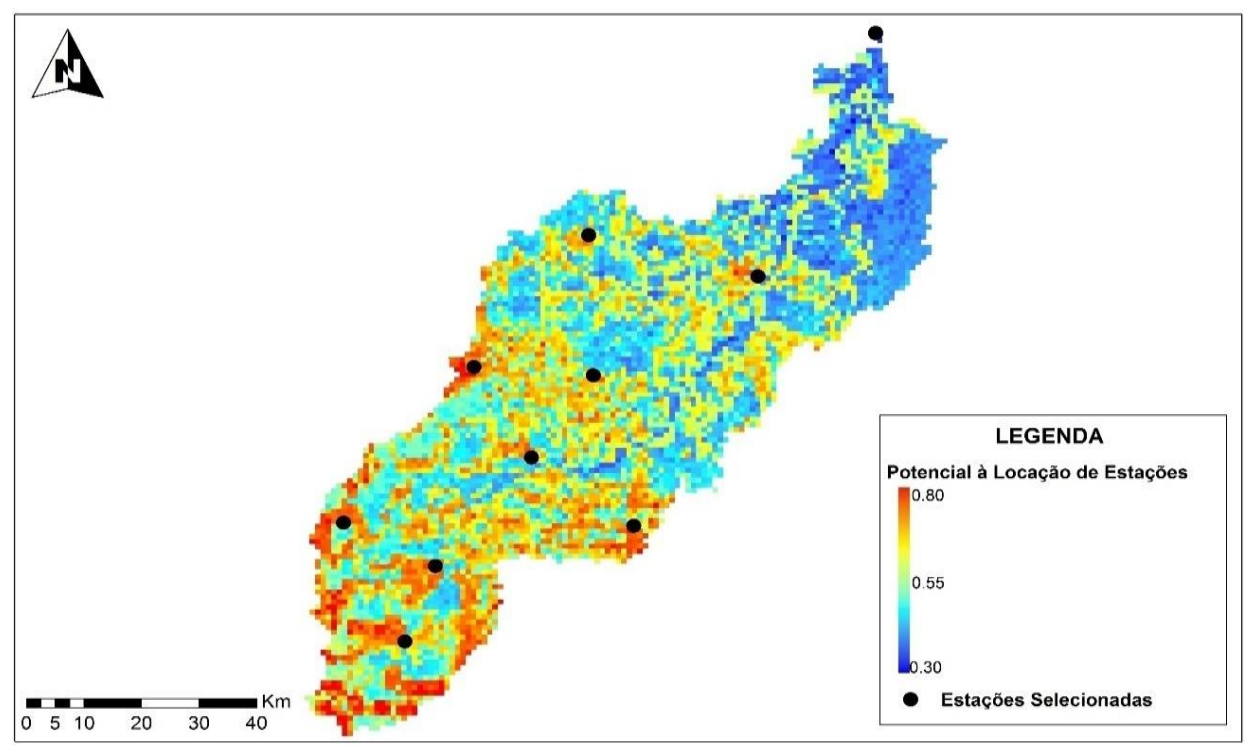

O fato acima destacado indicaria que, caso não fosse adotada a eliminação de estações com áreas de influência vizinhas, as possíveis localizações de estações culminariam na seleção das unidades nas zonas de nascente. Nesse sentido, aplicando esse critério e fixando a obrigatoriedade da presença de uma estação na foz da bacia, foi obtida uma rede melhor distribuída espacialmente.

Ao se ponderar, na abordagem metodológica, a questão de logística para alocação das estações, fez-se com que o mapa gerado praticamente impossibilitasse a presença de estações em áreas florestadas e com grande elevação. Todavia as possíveis localizações devem ser examinadas de forma parcimoniosa para verificar a real possibilidade de alocar a estação no ponto estimado, pois o método serve apenas de aporte indicativo na tomada de decisões. 


\section{CONCLUSÕES}

Em síntese, a metodologia proposta para o dimensionamento da rede hidrossedimentológica forneceu um quantitativo de 10 estações espalhadas ao longo da bacia, sendo uma delas no exutório e as demais em áreas com alto índice ponderado para alocação de estação.

Espera-se que a nova proposição de monitoramento hídrico-ambiental possa fornecer dados valiosos para a bacia do rio Machadinho no sentido de permitir efetuar estudos que subsidiem a melhor gestão dos recursos hídricos da região.

\section{AGRADECIMENTOS}

Inicialmente, os autores agradecem a bolsa de estudo concedida ao primeiro autor fornecida pelo CNPq - Conselho Nacional de Desenvolvimento Científico e Tecnológico. Agradecimentos são estendidos à FAPERJ, por meio dos projetos FAPERJ - Pensa Rio Edital 34/2014 (2014-2017) - E-26/010.002980/2014, FAPERJ no. E_12/2015 e no. E22/2016, bem como ao suporte oferecido pelo CNPq por meio do projeto Edital no 12/2016 Processo 306944/2016-2 e projeto Edital Universal no 14/2013 - Processo 485136/2013-9 e pela CAPES mediante o projeto MEC-CAPES/BRICS 2016 no. 23038009469/2016-58.

\section{REFERÊNCIAS}

BACCI, D. L. C. Esboço Geológico da Gleba Machadinho D’Oeste, RO. Governo de Rondônia, 2005.

BUTT, N.; OLIVEIRA, P. A.; HEIL COSTA, M. H.Evidence that deforestation affects the onset of the rainy season in Rondônia, Brazil. Journal of Geophysical Research, v. 116, n. D11120, p. 1-8, 2011.

CPRM - SERVIÇO GEOLÓGICO DO BRASIL - CPRM. Geologia e recursos minerais do estado de Rondônia, Porto Velho, 2007.

DIAS, F. S. Definição de Rede Adaptativa de Monitoramento Hidrometeorológico com Suporte de Sensoriamento Remoto na Bacia do Dois Rios - RJ. Dissertação de Mestrado em Engenharia Civil, COPPE, Universidade Federal do Rio de Janeiro, Rio de Janeiro, Rio de Janeiro, 2014. 
DINIZ, S. F.; MOREIRA, C. A.; CORRADINI, F. A. Susceptibilidade erosiva do baixo curso do rio Acaraú-CE. Geociênc., vol.27, n.3, pp. 355-367, 2008.

GALVÃO, W. S. Uso de SIG na geração de modelos de potencial à locação de estações fluviométricas e de regiões geoambientais homogêneas na bacia do rio São Francisco. Tese de Doutorado em Geologia, Universidade de Brasília, Brasília, 2004.

GOMES, F. B. Modos de ocupação no município de Machadinho D'Oeste /RO e suas relações com equilíbrio natural da paisagem e ajustes morfodinâmicos. Dissertação de M.Sc. Fundação Universidade Federal de Rondônia - UNIR, Mestrado em geografia, Porto Velho - RO, 2009.

GONTIJO JÚNIOR, W. C. Avaliação e redimensionamento de redes para o monitoramento fluviométrico utilizando o método Sharp e o conceito de entropia. Dissertação de Mestrado em Tecnologia Ambiental e Recursos Hídricos, Departamento de Engenharia Civil e Ambiental, Universidade de Brasília, Distrito Federal, 2007.

KRUSCHE, A. V. et al. Efeitos das mudanças do uso da terra na biogeoquímica dos corpos d'água da bacia do rio Ji-Paraná, Rondônia, Acta Amaz., Manaus, v. 35, n. 2, 2005.

QUADROS, M. L. E. S.; RIZOTTO, G. J. Geologia e recursos minerais do estado de Rondônia: Sistema de Informações Geográficas - SIG. Porto Velho: CPRM, 2007.

RONDÔNIA. Secretaria de Estado do Desenvolvimento Ambiental (SEDAM). Boletim Climatológico de Rondônia - 2008. Porto Velho, SEDAM, 2009.

SOUZA, V. A. S. Avaliação Hidrossedimentológica Com Suporte Do Modelo Swat Na Amazônia Ocidental - Bacia Do Rio Machadinho/RO. Dissertação de Mestrado em Engenharia Civil, Departamento de Engenharia Civil, Universidade Federal do Rio de Janeiro, Rio de Janeiro, 2015.

WMO - World Meteorological Organization, (1994). Guide to hydrological practices - data acquisition and processing, analysis, forecasting e others aplications. 15 ed. World Meteorological Organization $n^{\circ}$ 168. p. 259-287, 1984. 